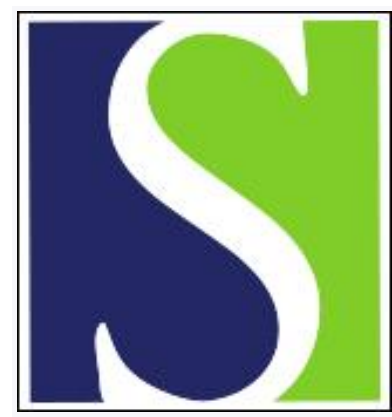

Scand J Work Environ Health Online-first -article

https://doi.org/10.5271/sjweh.2913

Published online: 29 Mar 2010

Physical demands at work, physical fitness, and 30-year ischaemic heart disease and all-cause mortality in the Copenhagen Male Study

by Holtermann A, Mortensen OS, Burr H, Søgaard K, Gyntelberg F, Suadicani P

Affiliation: National Research Centre for the Working Environment, Lersø Parkallé 105, 2100 Copenhagen Ø, Denmark. aho@nrcwe.dk

Refers to the following texts of the Journal: $2010 ; 36(5): 366-372$ 1991;17 suppl 1:99-109 2009;35(6):466-474 2007;33(6):405-424 2003;29(5):363-377

The following articles refer to this text: 2010;36(5):366-372; 2010;36(5):349-355; 2010;36(6):466-472; 2012;38(5):467-475; 2015;41(2):140-152; 2016;42(4):291-298; 2019;45(1):90-97; 2020;46(3):268-277; 2022;48(2):86-98; 2023;49(3):231-244

Key terms: all-cause mortality; cardiovascular health; Copenhagen Male Study; fitness; health; ischaemic heart disease; mortality; occupational health; occupational physical activity; physical activity; physical demands; physical fitness; work

This article in PubMed: www.ncbi.nlm.nih.gov/pubmed/20352174

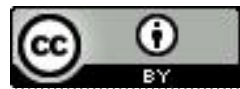




\title{
Physical demands at work, physical fitness, and 30-year ischaemic heart disease and all-cause mortality in the Copenhagen Male Study
}

\author{
by Andreas Holtermann, PhD, ${ }^{1}$ Ole Steen Mortensen, PhD, ${ }^{1,}{ }^{2}$ Hermann Burr, PhD, ${ }^{1}$ Karen Søgaard, PhD, ${ }^{3}$ \\ Finn Gyntelberg, DMSc, ${ }^{2}$ Poul Suadicani, DMSc ${ }^{2}$
}

\begin{abstract}
Holtermann A, Mortensen OS, Burr H, Søgaard K, Gyntelberg F, Suadicani P. Physical demands at work, physical fitness, and 30-year ischaemic heart disease and all-cause mortality in the Copenhagen Male Study. Scand J Work Environ Health. 2010;36(5):357-365.
\end{abstract}

\begin{abstract}
Objective No previous long-term prospective studies have examined if workers with low cardiorespiratory fitness have an increased risk of cardiovascular mortality due to high physical work demands. We tested this hypothesis.

Method We carried out a 30-year follow-up of the Copenhagen Male Study of 5249 employed men aged $40-59$ years. We excluded from follow-up 274 men with a history of myocardial infarction, prevalent symptoms of angina pectoris, or intermittent claudication. We estimated physical fitness [maximal oxygen consumption $\left.\left(\mathrm{VO}_{2} \mathrm{Max}\right)\right]$ using the Åstrand cycling test and determined physical work demands with two self-reported questions.
\end{abstract}

Results In the Copenhagen Male Study, 587 men (11.9\%) died due to ischaemic heart disease (IHD). Using men with low physical work demands as the reference group, Cox analyses - adjusted for age, blood pressure, smoking, alcohol consumption, body mass index, diabetes, and hypertension - showed that high physical work demands were associated with an increased risk of IHD mortality in the least fit $\left[\mathrm{VO}_{2} \mathrm{Max}\right.$ range $15-26, \mathrm{~N}=892$, hazard ratio (HR) $2.04,95 \%$ confidence interval $(95 \% \mathrm{CI}) 1.20-3.49$ ] and moderately fit $\left(\mathrm{VO}_{2} \mathrm{Max}\right.$ range $27-38, \mathrm{~N}=3037, \mathrm{HR} 1.75$, $95 \% \mathrm{CI} 1.24-2.46)$, but not among the most fit men ( $\mathrm{VO}_{2}$ Max range $39-78, \mathrm{~N}=1014$, HR $1.08,95 \% \mathrm{CI} 0.52-2.17$ ). We found a similar, although slightly weaker, relationship with respect to all-cause mortality.

Conclusions The hypothesis was supported. Men with low and medium physical fitness have an increased risk of cardiovascular and all-cause mortality if exposed to high physical work demands. Ours observations suggest that, among men with high physical work demands, being physically fit protects against adverse cardiovascular effects.

Key terms cardiovascular health; occupational health; occupational physical activity.

In a recent paper, Krause and colleagues (1) addressed the fact that the literature on the role of occupational physical activity as a risk factor for ischaemic heart disease (IHD) is conflicting, and that only a small number of studies have included information on both leisuretime and occupational physical activity.

In the Copenhagen Male Study, we found that, in contrast to physical activity during leisure time, exposure to high physical work demands is associated with an increased risk of IHD and all-cause mortality (2). Furthermore, we showed that a moderate or high level of physical activity during leisure time was associated with a lower risk of IHD and all-cause mortality irrespective of the level of physical demands at work (2).

It is well established that being sedentary during leisure time is associated with an increased risk of premature mortality $(3,4)$, so promoting physical activity during leisure time is recommended (5). Physical training rapidly increases physical fitness (6). Low physical fitness is an independent predictor of IHD and premature mortality (7-10). Physical fitness determines cardiovascular workload at any given level of physical work intensity (11). In other words, the lower the cardiorespiratory fitness a worker possesses, the higher

1 National Research Centre for the Working Environment, Copenhagen, Denmark.

2 The Copenhagen Male Study, Epidemiological Research Unit, Department of Occupational and Environmental Medicine, Bispebjerg University Hospital, Copenhagen NV, Denmark.

3 Institute of Sports Science and Clinical Biomechanics, University of Southern Denmark, Odense M, Denmark.

Correspondence to: Dr A Holtermann, National Research Centre for the Working Environment, Lersø Parkallé 105, 2100 Copenhagen $\emptyset$, Denmark. [E-mail: aho@nrcwe.dk] 
his cardiovascular workload will be when performing a physically demanding work task.

Two long-term cohort studies from Finland $(1,12)$ reported that, in contrast to energy expenditure during leisure-time physical activity, high energy consumption at work may have detrimental effects on cardiovascular health even when controlling for the level of physical activity during leisure time and other well-known risk factors for IHD. To our knowledge, no previous study, apart from that of Krause and colleagues (1), has concomitantly taken into account information on physical activity during leisure time and used an objective measure of physical fitness when studying the association of occupational physical work demands with risk of IHD. As an endpoint, Krause's study (1) used the carotid intima-media thickness, which is a reliable surrogate marker of coronary atherosclerosis and also an independent predictor of manifest coronary heart disease.

No previous long-term prospective studies have examined if workers with low cardiorespiratory fitness have an increased risk of cardiovascular mortality due to high physical work demands. We tested this hypothesis.

\section{Methods}

\section{Study population}

The Copenhagen Male Study was established in 1970 1971 and comprised 5249 (87\% of those invited to participate) male employees, aged 40-59 years, from 14 companies, covering the railway, public road construction, military, postal, telephone, customs, national bank, and medical industry sectors $(13,14)$.

The examination consisted of a questionnaire, a short interview, and a clinical examination including measurements of height, weight, and blood pressure. Indirect measurement of physical fitness [maximal oxygen consumption $\left(\mathrm{VO}_{2} \mathrm{Max}\right)$ ] was performed with a bicycle ergometer. Thirty-five men with orthopaedic problems, who were unable to perform the bicycle test, were excluded from the study.

From the questionnaire, we obtained information about working conditions, lifestyle, and general health, including history of myocardial infarction, angina pectoris, and intermittent claudication. The information given in the questionnaire was clarified with each subject in the ensuing interview. Details on the questionnaire have already been published (15). A number of these factors are elaborated in more detail below.

\section{Eligibility}

In addition to the 35 men unable to carry out the bicycle test, men with a history of myocardial infarction $(\mathrm{N}=74)$, angina pectoris $(\mathrm{N}=165)$ or intermittent claudication $(\mathrm{N}=105)$ were excluded from the prospective study. In total, the excluded group comprised these 274 men and 9 men with missing answers, leaving 4943 men for the incidence study. With respect to all variables included, missing values ranged from $0-2.7 \%$.

\section{Physical fitness}

Heart rate was measured during submaximal bicycle work in a steady state with the aid of a stopwatch and stethoscope. The loads used were 100, 150, and $200 \mathrm{~W}$. One, two, or in a few cases, three different loads were used. The load chosen in each case was determined by the weight and age of the person or heart rate during the first minute of the test; we determined the $\mathrm{VO}_{2}$ Max using Åstrand's nomogram (6). The correlation between directly and indirectly measured $\mathrm{VO}_{2} \mathrm{Max}$ is high. The method used has previously been described in detail (13).

\section{Physical activity at work, general description}

Physical activity during work was estimated by the following question: "Which description most precisely covers your pattern of physical activity at work?" Groups were defined according to the following responses: (i) You are mainly sedentary and do not walk much around at your workplace, for example, desk work, and work including assembling of minor parts (group 1); (ii) You walk around quite a bit at your workplace but do not have to carry heavy items, eg, light industrial work, nonsedentary office work, inspection and the like (group 2); (iii) Most of the time you walk, and you often have to walk up stairs and lift various items. Examples include mail delivery and construction work (group 3); (iv) You have heavy physical work. You carry heavy burdens and carry out physically strenuous work, eg, work including digging and shoveling (group 4). In the analyses, physical activity was defined as follows: group $1=$ low, group $2=$ medium; group $3=$ high (since only $2.4 \%$ belonged to group 4, groups 3 and 4 were pooled) and are referred to as high.

\section{Strenuous work}

Strenuous work was estimated from the question: "Do you perform strenuous work (work resulting in sweating)?" The answer options were: "often", "occasionally", and "seldom or never" and coded as follows: $1=$ seldom or never, $2=$ occasionally, and $3=$ often.

\section{Physical work activity, combined variable}

An additional variable was constructed in order to further distinguish between the presence or absence of 
physically demanding work. Summing up the values from the aforementioned questions on physical activity and strenuous work gave values ranging from 2-6. A low combined score of 2 was defined as "low physical work demands", a score of 3 or 4 was defined as "moderate physical work demands", and a score of 5 or 6 was defined as "high physical work demands".

\section{Physical activity during leisure time}

In order to determine this factor, the questionnaire asked "Which description most precisely covers your pattern of physical activity at leisure time?" with the following possible responses: (i) You are mainly sedentary, for example, you read, watch television, go to the cinema. In general you spend most of your leisure time performing sedentary tasks (group 1); (ii) You go for a walk, use your bicycle a little or perform activity for at least 4 hours per week, for example, light gardening, leisure-time building activity, table tennis and bowling (group 2); (iii) You are an active athlete, eg, run or play tennis or badminton for at least 3 hours/ week. If you frequently perform heavy gardening, you also belong to this group (group 3); (iv) You take part in competitive sports, swim, play European football, handball or run long distances regularly several times per week (group 4).

In the analyses, the level of physical activity during leisure time was defined as group $1=$ low, group $2=$ moderate, and group $3=$ high (since only $0.4 \%$ belonged to group 4 , groups 3 and 4 were pooled).

\section{Lifestyle factors}

The male workers reported if they were current smokers, previously smoked, or had never smoked. In addition, participants reported their daily average alcohol consumption as the number of alcoholic beverages consumed per day in the following categories: $0,1-2$, $3-5,6-10$, and $>10$.

\section{Clinical and health-related factors}

Based on height and weight measurements, body mass index (BMI) was calculated as $\mathrm{kg} / \mathrm{m}^{2}$. Blood pressure was measured with the subject seated and after at least five minutes rest. A $12 \mathrm{~cm}$ wide, $26 \mathrm{~cm}$ long cuff was firmly and evenly applied to the right upper arm with the lower edge of the cuff placed $2 \mathrm{~cm}$ antecubitally. Diastolic blood pressure was recorded at the point where the Korotkoff sounds disappeared (phase 5). In addition, the participants were asked if they received treatment for either hypertension or diabetes from their physician or elsewhere. The answer options were yes or no.

\section{Social class}

The men were divided into five social classes according to a system originally elaborated by Svalastoga and later adjusted by Hansen $(16,17)$ This classification system is based on education level and job position in terms of the number of subordinates. Typical jobs in the study cohort were: (i) officer, civil engineer, office executive, or head of department (social class I); (ii) head clerk or engineer (social class II); engine driver or train guard (social class III); machine fitter in a telephone company (social class IV); and unskilled laborer, mechanic, or driver (social class V).

\section{End-points}

We obtained information on death diagnoses between the period 1970-1971 to the end of 2001 from official national registers. The IHD mortality diagnoses included International Classification of Diseases' codes ICD-8: 410-14, and (from 1994) ICD-10: I20-I25.

\section{Statistical analysis}

We performed basic statistical analyses, Chi-squared analysis (likelihood ratio), analysis of variance, and regression analyses. We estimated relative risks (RR) by $\exp (\beta)$, where $\beta$ is the hazard coefficient for the variable of interest in a Cox's proportional hazards regression model with the maximum likelihood ratio method. Assumptions regarding the use of Cox's proportional hazards were met by inspection of the log minus log function as the covariate mean. A final Cox proportional hazards regression analyses, with IHD mortality as outcome, was performed to obtain a statistical expression for the conspicuous difference in the predictive value of physical work demands and IHD mortality between men with high and low physical fitness. In addition to the main effects of the two variables (physical fitness and physical work demands), age, lifestyle factors, alcohol consumption, and smoking habits, we included a multiplicative interaction term between physical fitness (highest fifth/others) and the three-group variable depicting the level of physical work demands. We took, a priori, as significant a two-sided probability value of $\mathrm{P}<0.05$.

\section{Results}

In the eligible study population of male employees who had completed the ergometer test and were without a history of myocardial infarction, angina pectoris, or intermittent claudication, 587 died (11.9\%) from IHD 
during the period 1970/1971-2001. During the same time, $2663(54.0 \%)$ died in total.

Table 1 shows lifestyle and other characteristics of men belonging to groups with different levels of physical fitness $\left(\mathrm{VO}_{2} \mathrm{Max}\right)$; lowest fifth: range 15-26; three intermediate fifths: range 27-38; and highest fifth: 39-78. The level of physical fitness was inversely associated with systolic and diastolic blood pressure, alcohol consumption, treatment due to hypertension, BMI, and age. No significant relationship was found between the level of fitness and social class. As previously reported, smokers surprisingly had higher levels of physical fitness (13).

Table 2 shows lifestyle and other characteristics of men belonging to different groups of self-assessed leisure-time physical activity. Compared to men with lower levels of physical activity during leisure time, men reporting higher levels were younger, had a higher level of physical fitness and lower systolic and diastolic blood pressure and BMI, while fewer were current smokers, consumed $\geq 6$ alcoholic beverages/day, belonged to low social class, and received treatment for hypertension.

Table 3 shows the lifestyle and other characteristics of men belonging to the different groups of physical activity level at work. We observed a significant positive correlation to physical fitness, although the association was less pronounced than that found between physical activity during leisure time and fitness as presented in table 2 . Also the level of occupational physical activity was positively correlated with smoking, alcohol use, BMI, and low social class.

Table 4 shows the association of baseline physical fitness, the level of physical activity during leisure time, and physical work demands with risk of IHD and allcause mortality. Men with high physical fitness had a 45\% lower risk of IHD mortality [age-adjusted hazard ratio (HR) $0.55,95 \%$ confidence interval $(95 \%$ CI) $0.42-0.73$ ] and a $38 \%$ lower risk of all-cause mortality (age-adjusted HR $0.62,95 \%$ CI $0.55-0.71$ ) compared to men with low physical fitness. Also men reporting moderate or high levels of leisure-time physical activity had a lower risk of both IHD and all-cause mortality compared to workers reporting low leisure-time physical activity. Of particular interest was the $50 \%$ reduced risk of IHD mortality among men who have a high compared to low level of physical activity during leisure time. In contrast, men with high physical work demands had a $69 \%$ increased risk of IHD mortality (age-adjusted HR 1.69, 95\% CI $1.31-2.17)$ and a $51 \%$ higher risk of all-cause mortality (age-adjusted HR 1.51, 95\% CI 1.34-1.70) compared to men with low physical work demands. The right column of the table shows the result of Cox analyses taking into

Table 1. Lifestyle and other characteristics according to measured physical fitness, maximal oxygen consumption $\left(\mathrm{VO}_{2} \mathrm{Max}\right)$ among men with no history of myocardial infarction, angina pectoris, or intermittent claudication. [SD=standard deviation; freq=frequency].

\begin{tabular}{|c|c|c|c|c|c|c|c|c|c|c|c|}
\hline & \multicolumn{9}{|c|}{ Level of physical fitness } & \multirow[t]{3}{*}{ P-value a } & \multirow[t]{3}{*}{ P-value ${ }^{b}$} \\
\hline & \multicolumn{3}{|c|}{$\begin{array}{l}\text { Lowest quintile }(\mathrm{N}=892) \\
\mathrm{VO}_{2} \mathrm{Max} \text { range } 15-26\end{array}$} & \multicolumn{3}{|c|}{$\begin{array}{c}3 \text { medium quintiles }(\mathrm{N}=3037) \\
\mathrm{VO}_{2} \text { Max range } 27-38\end{array}$} & \multicolumn{3}{|c|}{$\begin{array}{l}\text { Highest quintiles }(\mathrm{N}=1014 \text { ) } \\
\mathrm{VO}_{2} \text { Max range } 39-78\end{array}$} & & \\
\hline & Mean & $\mathrm{SD}$ & Freq $(\%)$ & Mean & SD & Freq $(\%)$ & Mean & $\mathrm{SD}$ & Freq $(\%)$ & & \\
\hline Physical fitness $\left(\mathrm{VO}_{2} \mathrm{Max}\right)$ & 23.5 & 2.3 & . & 32.2 & 3.3 & . & 43.8 & 4.8 & . & $\cdot$ & . \\
\hline \multicolumn{12}{|l|}{ Lifestyle factors 1970-1971 } \\
\hline \multicolumn{12}{|l|}{ Smoker } \\
\hline Current & . & . & 67.6 & . & . & 71.6 & . & . & 76.3 & & \\
\hline Previous & . & . & 23.2 & . & . & 19.1 & . & . & 15.4 & $<0.001$ & $<0.001$ \\
\hline Never & . & . & 9.2 & . & . & 9.3 & . & . & 8.3 & & \\
\hline \multicolumn{12}{|l|}{ Alcohol, beverages per 24 hours } \\
\hline 0 & . & . & 31.5 & . & . & 33.7 & . & . & 36.1 & & \\
\hline $1-2$ & . & . & 42.9 & . & . & 48.3 & . & . & 41.7 & $<0.001$ & $<0.001$ \\
\hline $3-5$ & . & . & 20.8 & . & . & 14.8 & . & . & 13.9 & & \\
\hline$\geq 6$ & . & . & 4.9 & . & . & 3.2 & . & . & 1.3 & & \\
\hline \multicolumn{12}{|l|}{ Clinical risk factors } \\
\hline Diabetes (treatment of) & . & . & 1.1 & . & . & 0.7 & . & . & 0.7 & 0.34 & 0.39 \\
\hline Systolic blood pressure (mm Hg) & 143.7 & 20.2 & & 134.5 & 18.3 & & 127.3 & 16.3 & . & $<0.001$ & 0.06 \\
\hline Diastolic blood pressure $(\mathrm{mm} \mathrm{Hg})$ & 87.2 & 12.2 & & 82.9 & 11.2 & & 79.3 & 10.7 & . & $<0.001$ & 0.29 \\
\hline Hypertension (treatment of) & . & . & 2.4 & . & . & 1.5 & . & . & 1.1 & 0.03 & 0.09 \\
\hline Body mass index $\left(\mathrm{kg} / \mathrm{m}^{2}\right)$ & 26.8 & 3.4 & & 25.2 & 2.8 & & 24.1 & 2.5 & . & $<0.001$ & 0.03 \\
\hline \multicolumn{12}{|l|}{ Other characteristics } \\
\hline Low social class (classes IV/V) & . & . & 56.3 & . & . & 54.7 & . & . & 54.7 & 0.51 & 0.71 \\
\hline Age (years) & 50.8 & 5.2 & & 48.5 & 5.3 & & 46.9 & 4.8 & . & $<0.001$ & 0.04 \\
\hline
\end{tabular}

a P-values of trend test (Kendall's tau B) or test for linearity in analysis of variance.

b P-values of Chi-square test or test for deviation in analysis of variance. 
Table 2. Physical fitness and other characteristics according to the level of leisure-time physical activity among men with no history of myocardial infarction, angina pectoris, or intermittent claudication. [SD=standard deviation; freq=frequency; $\mathrm{VO}_{2} \mathrm{Max}_{\mathrm{S}}$ maximal oxygen consumption]

\begin{tabular}{|c|c|c|c|c|c|c|c|c|c|c|c|}
\hline & \multicolumn{9}{|c|}{ Level of physical activity during leisure time } & \multirow[t]{3}{*}{ P-value a } & \multirow[t]{3}{*}{ P-value ${ }^{b}$} \\
\hline & \multicolumn{3}{|c|}{ Low $(N=814)$} & \multicolumn{3}{|c|}{ Medium $(\mathrm{N}=3514)$} & \multicolumn{3}{|c|}{ High $(\mathrm{N}=504)$} & & \\
\hline & Mean & SD & Freq $(\%)$ & Mean & $S D$ & Freq $(\%)$ & Mean & SD & Freq $(\%)$ & & \\
\hline & 31.1 & 6.6 & . & 33.0 & 7.0 & . & 36.9 & 8.2 & . & $<0.001$ & $<0.001$ \\
\hline \multicolumn{12}{|l|}{ Lifestyle factors 1970-1971 } \\
\hline \multicolumn{12}{|l|}{ Smoker } \\
\hline Current & . & . & 78.0 & . & . & 71.1 & . & . & 65.5 & & \\
\hline Previous & . & . & 14.9 & . & . & 19.8 & . & . & 21.4 & $<0.001$ & $<0.001$ \\
\hline Never & . & . & 7.1 & . & . & 9.1 & . & . & 13.1 & & \\
\hline \multicolumn{12}{|l|}{ Alcohol, beverages per 24 hours } \\
\hline 0 & . & . & 31.1 & . & . & 34.2 & . & . & 35.9 & & \\
\hline $1-2$ & . & . & 42.6 & . & . & 48.1 & . & . & 51.0 & $<0.001$ & $<0.001$ \\
\hline $3-5$ & . & . & 20.3 & . & . & 15.2 & . & . & 10.6 & & \\
\hline$\geq 6$ & . & . & 5.9 & . & . & 2.5 & . & . & 2.6 & & \\
\hline \multicolumn{12}{|l|}{ Clinical risk factors } \\
\hline Diabetes (treatment of) & . & . & 1.5 & . & . & 0.5 & . & . & 1.0 & 0.21 & 0.02 \\
\hline Systolic blood pressure $(\mathrm{mm} \mathrm{Hg})$ & 135.3 & 19.7 & & 134.7 & 18.8 & & 132.5 & 17.7 & . & 0.02 & 0.24 \\
\hline Diastolic blood pressure $(\mathrm{mm} \mathrm{Hg})$ & 83.8 & 11.8 & & 83.0 & 11.4 & & 80.8 & 10.7 & . & $<0.001$ & 0.06 \\
\hline Hypertension (treatment of) & & . & 2.1 & & . & 1.7 & . & . & 0.6 & 0.04 & 0.06 \\
\hline Body mass index $\left(\mathrm{kg} / \mathrm{m}^{2}\right)$ & 25.6 & 3.3 & & 25.3 & 2.9 & & 24.8 & 2.8 & . & $<0.001$ & 0.47 \\
\hline \multicolumn{12}{|l|}{ Other characteristics } \\
\hline Low social class (classes IV/V) & . & . & 61.8 & . & . & 54.0 & . & . & 47.9 & $<0.001$ & $<0.001$ \\
\hline Age (vears) & 49.3 & 5.5 & & 48.6 & 5.2 & & 47.5 & 5.2 & . & $<0.001$ & 0.21 \\
\hline
\end{tabular}

a P-values of trend test (Kendall's tau B) or test for linearity in analysis of variance.

b P-values of Chi-square test or test for deviation in analysis of variance.

account, in addition to age, relevant potential confounders as identified in tables $1-3$. As could be expected, the associations were somewhat attenuated for all three predictor variables, but the overall trend remained. In particular, the association of fitness with the risk of IHD mortality was affected by the inclusion of blood pressure variables and yet, the trend persisted.

Table 5 shows the risk of IHD and all-cause mortality during follow-up among men with low, medium, and high physical fitness, stratified according to the level of physical work demands. The results of Cox proportional hazard analyses, including different potentially confounding variables, are presented. Among men with low and medium physical fitness levels, men with high physical work demands had a significantly twofold increased risk of IHD when adjusted for age only. Further adjustment did not materially influence this result. In contrast, among the fittest men, who overall had the lowest risk, no association was found between increasing physical work demands and the risk of IHD mortality.

Among men with the lowest level of physical fitness, those with high physical work demands had a $43 \%$ significantly higher risk for all-cause mortality than men with low demands. This difference was attenuated to a non-significant level when controlling for potential confounders. Among men with a medium level of physical fitness, the largest group, those with high physical work demands had a $60 \%$ significantly higher risk for all-cause mortality than men with low demands. This difference was also attenuated when controlling for potential confounders but remained statistically significant. Among men with the highest level of physical fitness, those with high physical work demands had a 33\% non-statistically significant increased risk of all-cause mortality when controlling for age only. This estimate did not materially change with further adjustment.

In two additional analyses, we further tested the relative importance of physical fitness as an effect modifier for the association between physical work demands and mortality (data not shown). We carried out an ageadjusted Cox analysis including an interaction term between physical work demands and physical fitness level with risk of IHD mortality as the endpoint. When we included smoking habits and alcohol consumption, following a backward elimination procedure, the interaction was highly significant $(\mathrm{P}=0.002)$. We also carried out an age-adjusted Cox analysis including an interaction term between physical work demands and physical fitness level with risk of all-cause mortality as the endpoint. When smoking habits and alcohol consumption were included, following a backward elimination procedure, the interaction was not significant $(\mathrm{P}=0.22)$.

In the analyses presented in the tables, we pooled the three medium (intermediate) quintiles covering the 
Table 3. Lifestyle and other characteristics according to physical work demands based on the combined activity variable (general physical work demands and strenuous work resulting in sweating) among men without history of myocardial infarction, angina pectoris, or intermittent claudication. [SD = standard deviation; $\mathrm{VO}_{2} \mathrm{Max}=$ maximal oxygen consumption]

\begin{tabular}{|c|c|c|c|c|c|c|c|c|c|c|c|}
\hline & \multicolumn{9}{|c|}{ Physical work demands } & \multirow[t]{3}{*}{$\mathrm{P}$-value ${ }^{a}$} & \multirow[t]{3}{*}{ P-value ${ }^{b}$} \\
\hline & \multicolumn{3}{|c|}{ Low $(N=1239)$} & \multicolumn{3}{|c|}{ Medium ( $N=2661)$} & \multicolumn{3}{|c|}{ High $(\mathrm{N}=860)$} & & \\
\hline & Mean & SD & $\begin{array}{l}\text { Frequency } \\
(\%)\end{array}$ & Mean & $S D$ & $\begin{array}{c}\text { Frequency } \\
(\%)\end{array}$ & Mean & SD & $\begin{array}{c}\text { Frequency } \\
(\%)\end{array}$ & & \\
\hline Physical fitness ( $\left.\mathrm{VO}_{2} \mathrm{Max}\right)$ & 32.6 & 7.1 & . & 33.1 & 7.3 & . & 33.9 & 7.4 & . & $<0.001$ & 0.69 \\
\hline \multicolumn{12}{|l|}{ Leisure-time physical activity } \\
\hline Low & . & . & 18.9 & . & . & 15.6 & . & . & 17.2 & & \\
\hline Medium & . & . & 70.4 & . & . & 75.2 & . & . & 69.3 & 0.07 & $<0.001$ \\
\hline High & $\cdot$ & . & 10.7 & . & . & 9.2 & $\cdot$ & $\cdot$ & 13.4 & & \\
\hline \multicolumn{12}{|l|}{ Lifestyle factors 1970-1971 } \\
\hline \multicolumn{12}{|l|}{ Smoker } \\
\hline Current & . & . & 66.6 & . & . & 72.2 & . & . & 76.4 & & \\
\hline Previous & . & . & 22.4 & . & . & 19.0 & . & . & 15.6 & $<0.001$ & $<0.001$ \\
\hline Never & . & . & 11.1 & . & . & 8.8 & . & . & 8.0 & & \\
\hline \multicolumn{12}{|l|}{ Alcohol, beverages per 24 hours } \\
\hline 0 & . & . & 38.8 & . & . & 34.3 & . & . & 25.9 & & \\
\hline $1-2$ & . & . & 50.8 & . & . & 47.6 & . & . & 42.0 & $<0.001$ & $<0.001$ \\
\hline $3-5$ & . & . & 9.2 & . & . & 15.4 & . & . & 25.1 & & \\
\hline$\geq 6$ & . & . & 1.1 & . & . & 2.8 & . & . & 7.0 & & \\
\hline \multicolumn{12}{|l|}{ Clinical risk factors } \\
\hline Diabetes (treatment of) & . & . & 0.9 & . & . & 0.6 & . & . & 1.2 & 0.71 & 0.19 \\
\hline Systolic blood pressure $(\mathrm{mm} \mathrm{Hg})$ & 134.8 & 18.5 & & 134.6 & 19.0 & & 134.1 & 19.5 & . & 0.56 & 0.73 \\
\hline Diastolic blood pressure $(\mathrm{mm} \mathrm{Hg})$ & 83.3 & 11.5 & & 82.8 & 11.4 & & 82.9 & 11.7 & . & 0.30 & 0.40 \\
\hline Hypertension (treatment of) & & . & 1.9 & . & . & 1.6 & . & . & 1.5 & 0.51 & 0.78 \\
\hline Body mass index $\left(\mathrm{kg} / \mathrm{m}^{2}\right)$ & 24.7 & 2.8 & & 25.3 & 3.0 & & 25.9 & 3.1 & . & $<0.001$ & 0.86 \\
\hline \multicolumn{12}{|l|}{ Other characteristics } \\
\hline Low social class (classes IV/V) & . & . & 21.7 & . & . & 58.9 & . & . & 91.3 & $<0.001$ & $<0.001$ \\
\hline Age (years) & 48.7 & 5.3 & & 48.6 & 5.3 & & 48.6 & 5.2 & . & 0.73 & 0.66 \\
\hline
\end{tabular}

a P-values of trend test (Kendall's tau B) or test for linearity in analysis of variance.

${ }^{b} \mathrm{P}$-values of Chi-square test or test for deviation in analysis of variance.

$\mathrm{VO}_{2} \mathrm{Max}$ range $27-38$. In order to identify a possible threshold value for a protective effect of physical fitness on possibly adverse effects on IHD mortality from high physical work demands, we looked at the risk of IHD associated with work demands within all quintiles (data not shown). Except for the highest quintile (ie, $\mathrm{VO}_{2} \mathrm{Max}$ range 39-78), we consistently observed a positive gradient between increasing work demands and IHD risk.

\section{Discussion}

Our hypothesis that the level of physical fitness modifies the association between high physical work demands and the risk of IHD mortality was supported. We observed an increased risk of IHD mortality associated with increasing physical work demands among men with low and medium levels of physical fitness that was absent among the most physically fit men. Similar results were found for all-cause mortality, with the possible excep- tion that even the most-fit men who were exposed to high physical work demands had a $25 \%$ increased risk of all-cause mortality, although this latter finding was not statistically significant.

\section{Physical work demands, fitness, and IHD mortality}

Our study extends the old notion of physical fitness being a critical individual resource, not only for the performance of a physically demanding job $(18,19)$, but also to survive its effects.

Physical fitness is a well-documented prognostic factor for premature cardiovascular and all-cause mortality (7-10). The findings of a $25 \%$ lower risk for IHD mortality and 29\% lower risk for all-cause mortality among men with high compared to low physical fitness (table 4) support the importance of physical fitness. Of particular clinical interest was the considerably lower systolic and diastolic blood pressure among men with high versus low physical fitness (systolic blood pressure of 127 versus $144 \mathrm{mmHg}$ and diastolic blood pressure of 79 versus $87 \mathrm{mmHg}$ ). Men with high physical work 
Table 4. Physical fitness and physical activity during work and leisure time as predictors of ischaemic heart disease and all-cause mortality during 1970-71 to end of 2001 among men without history of myocardial infarction, angina pectoris or intermittent claudication at baseline. [ $\mathrm{HR}=$ hazard ratio; $95 \% \mathrm{Cl}=95 \%$ confidence interval; $\mathrm{VO}_{2} \mathrm{Max}=$ maximal oxygen consumption]

\begin{tabular}{|c|c|c|c|c|c|c|c|}
\hline & \multicolumn{2}{|c|}{ Mortality } & \multirow{2}{*}{$\begin{array}{c}\text { Incidence per } \\
100000 \text { person years }\end{array}$} & \multirow[t]{2}{*}{$\mathrm{HR}^{\mathrm{a}}$} & \multirow[t]{2}{*}{$95 \% \mathrm{Cl}$} & \multirow[t]{2}{*}{$H^{b}$} & \multirow[t]{2}{*}{$95 \% \mathrm{Cl}$} \\
\hline & N & $\%$ & & & & & \\
\hline \multicolumn{8}{|l|}{ Ischemic heart disease mortality } \\
\hline \multicolumn{8}{|l|}{ Physical fitness, $\mathrm{VO}_{2} \mathrm{Max}$} \\
\hline $\begin{array}{l}\text { Lowest quintile, } 15-26 \text { range }(\mathrm{N}=892) \\
\text { Medium quintiles, } 27-38 \text { range }(\mathrm{N}=3037) \\
\text { Highest quintiles, } 39-78 \text { range }(\mathrm{N}=1014)\end{array}$ & $\begin{array}{r}148 \\
354 \\
85\end{array}$ & $\begin{array}{r}16.6 \\
11.7 \\
8.4\end{array}$ & $\begin{array}{l}719 \\
468 \\
315\end{array}$ & $\begin{array}{l}1.00 \\
0.75 \\
0.55\end{array}$ & $\begin{array}{l}0.62-0.91 \\
0.42-0.73\end{array}$ & $\begin{array}{l}1.00^{c} \\
0.88 \\
0.75\end{array}$ & $\begin{array}{l}0.72-1.09 \\
0.56-1.00\end{array}$ \\
\hline \multicolumn{8}{|l|}{ Leisure time physical activity } \\
\hline $\begin{array}{l}\text { Low }(\mathrm{N}=814) \\
\text { Moderate }(\mathrm{N}=3514) \\
\text { High }(\mathrm{N}=504)\end{array}$ & $\begin{array}{r}128 \\
398 \\
40\end{array}$ & $\begin{array}{r}15.7 \\
11.4 \\
8.0\end{array}$ & $\begin{array}{l}667 \\
449 \\
304\end{array}$ & $\begin{array}{l}1.00 \\
0.67 \\
0.49\end{array}$ & $\begin{array}{r}. \\
0.55-0.82 \\
0.34-0.70\end{array}$ & $\begin{array}{l}1.00^{d} \\
0.72 \\
0.59\end{array}$ & $\begin{array}{l}0.58-0.88 \\
0.41-0.85\end{array}$ \\
\hline \multicolumn{8}{|l|}{ Physical work demands } \\
\hline $\begin{array}{l}\text { Low }(\mathrm{N}=1239) \\
\text { Moderate }(\mathrm{N}=2661) \\
\text { High }(\mathrm{N}=860)\end{array}$ & $\begin{array}{l}123 \\
317 \\
121\end{array}$ & $\begin{array}{l}10.0 \\
11.9 \\
14.1\end{array}$ & $\begin{array}{l}385 \\
477 \\
588\end{array}$ & $\begin{array}{l}1.00 \\
1.30 \\
1.69\end{array}$ & $\begin{array}{r}\cdot \\
1.05-1.60 \\
1.31-2.17\end{array}$ & $\begin{array}{l}1.00^{\mathrm{e}} \\
1.26 \\
1.55\end{array}$ & $\begin{array}{l}1.02-1.56 \\
1.19-2.02\end{array}$ \\
\hline \multicolumn{8}{|l|}{ All-cause mortality } \\
\hline \multicolumn{8}{|l|}{ Physical fitness, $\mathrm{VO}_{2} \mathrm{Max}$} \\
\hline $\begin{array}{l}\text { Lowest quintile, } 15-26 \text { range }(\mathrm{N}=892) \\
\text { Medium quintiles, } 27-38 \text { range }(\mathrm{N}=3037) \\
\text { Highest quintiles, } 39-78 \text { range }(\mathrm{N}=1014)\end{array}$ & $\begin{array}{r}610 \\
1630 \\
423\end{array}$ & $\begin{array}{l}68.5 \\
53.8 \\
41.9\end{array}$ & $\begin{array}{l}2962 \\
2156 \\
1567\end{array}$ & $\begin{array}{l}1.00 \\
0.81 \\
0.62\end{array}$ & $\begin{array}{r}. \\
0.74-0.89 \\
0.55-0.71\end{array}$ & $\begin{array}{l}1.00^{c} \\
0.87^{\prime} \\
0.71\end{array}$ & $\begin{array}{l}0.79-0.96 \\
0.62-0.81\end{array}$ \\
\hline \multicolumn{8}{|l|}{ Leisure time physical activity } \\
\hline $\begin{array}{l}\text { Low }(N=814) \\
\text { Moderate }(N=3514) \\
\text { High }(N=504)\end{array}$ & $\begin{array}{r}526 \\
1845 \\
218\end{array}$ & $\begin{array}{l}64.6 \\
52.6 \\
43.5\end{array}$ & $\begin{array}{l}2742 \\
2084 \\
1659\end{array}$ & $\begin{array}{l}1.00 \\
0.74 \\
0.62\end{array}$ & $\begin{array}{r}. \\
0.67-0.82 \\
0.53-0.72\end{array}$ & $\begin{array}{l}1.00^{d} \\
0.81 \\
0.74\end{array}$ & $\begin{array}{l}0.74-0.90 \\
0.63-0.87\end{array}$ \\
\hline \multicolumn{8}{|l|}{ Physical work demands } \\
\hline $\begin{array}{l}\text { Low }(\mathrm{N}=1239) \\
\text { Moderate }(\mathrm{N}=2661) \\
\text { High }(\mathrm{N}=860)\end{array}$ & $\begin{array}{r}598 \\
1436 \\
523\end{array}$ & $\begin{array}{l}48.5 \\
54.1 \\
60.8\end{array}$ & $\begin{array}{l}1872 \\
2164 \\
2543\end{array}$ & $\begin{array}{l}1.00 \\
1.22 \\
1.51\end{array}$ & $\begin{array}{r}. \\
1.11-1.34 \\
1.34-1.70\end{array}$ & $\begin{array}{l}1.00^{\mathrm{e}} \\
1.17 \\
1.33\end{array}$ & $\begin{array}{l}1.06-1.29 \\
1.18-1.51\end{array}$ \\
\hline
\end{tabular}

demands have previously been reported to have lower levels of physical fitness than men with low physical work demands (ie, sedentary workers) (19). In this study, men with high occupational physical demands had a slightly higher physical fitness compared to those with low physical work demands (33.9 versus $32.6 \mathrm{VO}_{2} \mathrm{Max}$ ). In comparison, men reporting a high level of leisuretime physical activity had a much higher physical fitness than men classifying themselves as basically sedentary during leisure time (36.9 versus $\left.31.1 \quad \mathrm{VO}_{2} \mathrm{Max}\right)$. This finding indicates that high physical work demands generally only have a minor influence on physical fitness, and highlights the significance of physical activity during leisure time for improving the aerobic capacity.

Men with high levels of fitness were observed to have a non-significant enhanced risk (25\%) for allcause mortality from high physical work demands. This finding indicates that men with high physical fitness cannot be excluded from having an enhanced risk for all-cause mortality from high physical work demands. This aspect needs to be further investigated in a larger population among men with high physical fitness.

In this study, we observed that a relatively low proportion of the male employees $(\sim 20 \%)$ have sufficiently high fitness to protect them from the increased risk for IHD and all-cause mortality resulting from high physical work demands. Previous studies from two Nordic countries $(1,20)$ have shown that a relatively high proportion of employees $(\sim 30 \%)$ have an energy expenditure at work that is in excess of the recommended maximum level of occupational aerobic strain (11). A dual prevention strategy, consisting of both fitness-enhancing physical exercise and tailoring of physical work demands with respect to the physical fitness of the employee may, in 
Table 5. Physical work demands and risk of ischaemic heart disease (IHD) and all-cause mortality 1970-71 to end of 2001 according to level of physical fitness: lowest quintile, three medium quintiles, and highest quintile. Different adjustment criteria are applied in Cox proportional hazards regression analyses with forced entry of variables. [HR = hazard ratios; $95 \% \mathrm{Cl}=95 \%$ confidence intervals]

\begin{tabular}{|c|c|c|c|c|c|c|c|c|c|c|}
\hline \multirow[t]{2}{*}{ Physical work demands } & \multicolumn{5}{|c|}{ IHD mortality } & \multicolumn{5}{|c|}{ All-cause mortality } \\
\hline & $\begin{array}{c}\text { Crude } \\
\text { incidence } \\
(\%)\end{array}$ & $\mathrm{HR}^{\mathrm{a}}$ & $95 \% \mathrm{Cl}$ & $\mathrm{HR}^{\mathrm{b}}$ & $95 \% \mathrm{Cl}$ & $\begin{array}{l}\text { Crude } \\
\text { incidence } \\
(\%)\end{array}$ & $\mathrm{HR}^{\mathrm{a}}$ & $95 \% \mathrm{Cl}$ & $\mathrm{HR}^{\mathrm{b}}$ & $95 \% \mathrm{Cl}$ \\
\hline \multicolumn{11}{|c|}{ Low physical fitness ( $N=838)$} \\
\hline $\begin{array}{l}\text { Low }(\mathrm{N}=242) \\
\text { Moderate }(\mathrm{N}=468) \\
\text { High }(\mathrm{N}=128)\end{array}$ & $\begin{array}{ll}13.7 & 1 \\
16.5 & 1 \\
22.7 & 1\end{array}$ & $\begin{array}{l}1.00^{\mathrm{c}} \\
1.28^{-} \\
1.98^{\mathrm{d}}\end{array}$ & $\begin{array}{r}. \\
0.85-1.93 \\
1.20-3.26\end{array}$ & $\begin{array}{l}1.00^{\mathrm{c}} \\
1.33^{\mathrm{d}} \\
2.04^{\mathrm{d}}\end{array}$ & $\begin{array}{r}. \\
0.87-2.03 \\
1.20-3.49\end{array}$ & $\begin{array}{l}63.9 \\
69.2 \\
75.8\end{array}$ & $\begin{array}{l}1.00^{\mathrm{c}} \\
1.18^{-} \\
1.43^{\mathrm{d}}\end{array}$ & $\begin{array}{r}0 \\
0.97-1.43 \\
1.11-1.85\end{array}$ & $\begin{array}{l}1.00^{c} \\
1.09 \\
1.20\end{array}$ & $\begin{array}{r}\cdot \\
0.89-1.33 \\
0.91-1.57\end{array}$ \\
\hline \multicolumn{11}{|c|}{ Moderate physical fitness ( $N=2916$ ) } \\
\hline $\begin{array}{l}\text { Low }(N=755) \\
\text { Moderate }(N=1625) \\
\text { High }(N=536)\end{array}$ & $\begin{array}{r}9.0 \\
11.8 \\
14.2\end{array}$ & $\begin{array}{l}1.00^{\mathrm{c}} \\
1.45^{\mathrm{d}} \\
1.89^{\mathrm{f}}\end{array}$ & $\begin{array}{r}. \\
1.10-2.62 \\
1.39-2.62\end{array}$ & $\begin{array}{l}1.00^{\mathrm{c}} \\
1.39^{\mathrm{e}} \\
1.75^{\mathrm{f}}\end{array}$ & $\begin{array}{r}. \\
1.05-1.84 \\
1.24-2.46\end{array}$ & $\begin{array}{l}45.8 \\
54.5 \\
62.1\end{array}$ & $\begin{array}{l}1.00^{\mathrm{c}} \\
1.33^{f} \\
1.60^{f}\end{array}$ & $\begin{array}{r}.17-1.50 \\
1.43-1.93\end{array}$ & $\begin{array}{l}1.00^{c} \\
1.25^{\dagger} \\
1.45^{\dagger}\end{array}$ & $\begin{array}{r}. \\
1.10-1.42 \\
1.24-1.70\end{array}$ \\
\hline \multicolumn{11}{|c|}{ High physical fitness ( $N=983)$} \\
\hline $\begin{array}{l}\text { Low }(\mathrm{N}=233) \\
\text { Moderate }(\mathrm{N}=558) \\
\text { High }(\mathrm{N}=192)\end{array}$ & $\begin{array}{l}8.7 \\
8.3 \\
8.3\end{array}$ & $\begin{array}{l}1.00^{c} \\
0.96 \\
1.08\end{array}$ & $\begin{array}{r}. \\
0.57-1.62 \\
0.56-2.09\end{array}$ & $\begin{array}{l}1.00^{c} \\
1.02 \\
1.08\end{array}$ & $\begin{array}{r}. \\
0.60-1.76 \\
0.52-2.17\end{array}$ & $\begin{array}{l}40.7 \\
40.1 \\
46.9\end{array}$ & $\begin{array}{l}1.00^{c} \\
1.00 \\
1.33\end{array}$ & $\begin{array}{r}. \\
0.79-1.28 \\
0.98-1.75\end{array}$ & $\begin{array}{l}1.00^{c} \\
1.00 \\
1.25\end{array}$ & $\begin{array}{l}0.78-1.28 \\
0.92-1.69\end{array}$ \\
\hline
\end{tabular}

${ }^{a}$ Adjusted for age.

${ }^{\mathrm{b}}$ Adjusted for all potential confounders: age, body mass index, systolic and diastolic blood pressure, treatment of diabetes or hypertension, alcohol use, and smoking (current, never, previous).

c Reference.

d $P \leq 0.01$.

e $P \leq 0.05$.

${ }^{+} \mathrm{P} \leq 0.001$.

theory, reduce the risk of IHD and all-cause mortality among employees with high physical work demands. Neither the individual's fitness level nor the occupational physical work demands are the sole responsibility of the worker. A great potential for prevention may exist by reducing the load of physical work tasks and allowing people with physically demanding work, even after the reduction of the workload, to receive physical training during working hours.

\section{Methodological considerations}

A methodological aspect of this study is that the occupational and leisure-time physical activity information was based on self-assessment, which invariably entails some degree of misclassification (21). However, no technical equipment for measuring daily physical activity at work and during leisure time was available in 1970, at least not in Denmark. In addition, the lack of continuous exposure data and repeated measures of exposure during the relatively long follow-up period may have contributed to a misclassification of exposure. The study population of the Copenhagen Male Study is urban Danish male workers, aged 40-59 years in 1970-1971. It is unknown whether the findings of this study are relevant also for females, younger workers, self-employed individuals or workers from other (eg, rural) communities and nationalities. Workers with pre-existing cardiovascular diseases were excluded from this study. However, a positive but statistically non-significant association was found between physical demands at work and all-cause mortality, and a high physical fitness was associated with a substantially reduced risk for IHD and all-cause mortality (22)

\section{Concluding remarks}

Men with low and medium levels of physical fitness have an increased risk of cardiovascular and all-cause mortality if exposed to high physical work demands. Due to the relatively small size of the population who could be classified as being highly fit in this study, further investigation of the risk for mortality from high physical work demands in larger populations with high physical fitness is recommended. Our observations suggest that - among men with high physical work demands - being physically fit protects against adverse cardiovascular effects.

\section{References}

1. Krause N, Brand RJ, Kaplan GA, Kauhanen J, Malla S, Tuomainen T-P, et al. Occupational physical activity, energy expenditure and 11-year progression of carotid atherosclerosis. Scand J Work Environ Health. 2007;33(6):405-24. 
2. Holtermann A, Mortensen OS, Burr H, Søgaard K, Gyntelberg F, Suadicani P. The interplay between physical activity at work and during leisure time - risk of ischemic heart disease and allcause mortality in middle-aged Caucasian men. Scand J Work Environ Health. 2009;35(6):466-74.

3. Mokdad AH, Marks JS, Stroup DF, Gerberding JL. Actual causes of death in the United States, 2000. JAMA. 2005;293(3):293-4.

4. Leitzmann MF, Park Y, Blair A, Ballard-Barbash R, Mouw T, Hollenbeck AR, et al. Physical activity recommendations and decreased risk of mortality. Arch Intern Med. 2007;167(22):2453-60.

5. Haskell WL, Lee IM, Pate RR, Powell KE, Blair SN, Franklin BA, et al. Physical activity and public health: updated recommendation for adults from the American College of Sports Medicine and the American Heart Association. Med Sci Sports Exerc. 2007;39(8):1423-34.

6. Åstrand P-O, Rodahl K. Textbook of work physiology. Physiological bases of exercise. New York (NY): McGrawHill Book Company; 1986.

7. Blair SN, Kampert JB, Kohl HW, Barlow CE, Macera CA, Paffenbarger RS, et al. Influences of cardiorespiratory fitness and other precursors on cardiovascular disease and all-cause mortality in men and women. JAMA. 1996;276(3):205-10.

8. Blair SN, Kohl HW, Paffenbarger RS, Clark DG, Cooper $\mathrm{KH}$, Gibbons LW. Physical-fitness and all-cause mortality - a prospective-study of healthy-men and women. JAMA. 1989;262(17):2395-401.

9. Erikssen G, Liestøl K, Bjørnholt J, Thaulow E, Sandvik L, Erikssen J. Changes in physical fitness and changes in mortality. Lancet. 1998;352(9130):759-62.

10. Hein HO, Suadicani P, Gyntelberg F. Physical-fitness or physical activity as a predictor of ischemic heart disease?: a 17-year follow-up in the Copenhagen Male Study. J Intern Med. 1992;232(6):471-9.

11. Aminoff T, Smolander J, Korhonen O, Louhevaara V. Prediction of acceptable physical work loads based on responses to prolonged arm and leg exercise. Ergonomics. 1998;41(1):109-20.
12. Virkkunen H, Härmä M, Kauppinen T, Tenkanen L. Shift work, occupational noise and physical workload with ensuing development of blood pressure and their joint effect on the risk of coronary heart disease. Scand J Work Environ Health. 2007;33(6):425-34.

13. Gyntelberg F. Physical fitness and coronary heart-disease male residents in copenhagen aged 40-59. Dan Med Bull. $1973 ; 20(1): 1-4$.

14. Gyntelberg F. One-year and 2-years incidence of myocardialinfarction in copenhagen males aged 40-59. Dan Med Bull. $1975 ; 22(2): 81-4$

15. Hein HO, Suadicani P, Gyntelberg F. Ischaemic heart disease incidence by social class and form of smoking: the Copenhagen Male Study - 17 years' follow-up. J Intern Med. 1992;231(5):477-83.

16. Svalastoga K. Prestige, class and mobility. Copenhagen: Munksgaard; 1959.

17. Hansen EJ. Social groups in Denmark. Copenhagen: The Danish National Centre for Social Research; 1984.

18. Brody S, Lardy HA. Bioenergetics and growth. J Phys Chem. 1946;50(2):168-9.

19. Ilmarinen J, Vouhevaara V, Korhonen O, Nygård CH, Hakola $\mathrm{T}$, Suvanto S. Changes in maximal cardiorespiratory capacity among aging municipal employees. Scand J Work Environ Health. 1991;17 suppl 1:99-109.

20. Karlqvist LK, Harenstam A, Leijon O, Scheele P. Excessive physical demands in modern worklife and characteristics of work and living conditions of persons at risk. Scand J Work Environ Health. 2003;29(5):363-77.

21. Sallis JF, Saelens BE. Assessment of physical activity by selfreport: status, limitations, and future directions. Res Q Exerc Sport. 2000;71(2):S1-S14

22. Holtermann A, Mortensen OS, Burr H, Søgaard K, Gyntelberg F, Suadicani P. Fitness, work, and leisure-time physical activity and ischaemic heart disease and all-cause mortality among men with pre-existing cardiovascular disease. Scand J Work Environ Health. 2010;36(5):366-372.

Received for publication: 5 November 2009 